\title{
Acute effects of hemodialysis on oxidative stress parameters in chronic uremic patients: Comparison of two dialysis membranes
}

This article was published in the following Dove Press journal: International Journal of Nephrology and Renovascular Disease 6 April 2010

Number of times this article has been viewed

\author{
H Ibrahim Varan' \\ Belda Dursun ${ }^{2}$ \\ Evrim Dursun ${ }^{3}$ \\ Tomris Ozben ${ }^{3}$ \\ Gultekin Suleymanlar ${ }^{4}$ \\ 'Numune Training Hospital, Division \\ of Nephrology, Medical School, \\ Adana; ${ }^{2}$ Division of Nephrology, \\ Medical School, Pamukkale \\ University, Denizli; ${ }^{3}$ Department \\ of Biochemistry, Medical School, \\ Akdeniz University, Antalya; \\ ${ }^{4}$ Division of Nephrology, Medical \\ School, Akdeniz University, Turkey
}

Correspondence: Belda Dursun Division of Nephrology, Department of Medicine, Medical School, Pamukkale University, Kinikli Campus, 20070, Denizli, Turkey

Tel +9258 2II 8585 ex. 2135

$\mathrm{Fax}+92582134922$

Email beldal@yahoo.com

\begin{abstract}
Uremic state and hemobioincompatibility are implicated in subclinical inflammation and oxidative stress and progression of atherosclerosis in the hemodialysis (HD) population. To what extent different dialysis membranes contribute to oxidative stress induced by a dialysis procedure per se is still a subject of debate. Fifteen HD patients and 15 healthy controls were enrolled in this study. Patients received two index HD sessions with a cuprophane and polysulfone membrane two weeks apart. Blood samples were collected at baseline and then before and after HD sessions. We determined serum thiobarbituric acid, protein carbonyl, and serum nitrite/nitrate levels as markers of oxidative damage. We also measured erythrocyte glutathione level, catalase, superoxide dismutase and glutathione peroxidase activity, and serum vitamin $\mathrm{C}$ and $\mathrm{E}$ levels as antioxidant markers. At baseline, HD patients, in comparison with normal controls, had a trend towards increased oxidant state and depletion of antioxidants. Cuprophane dialysis induced a higher increase in production of oxidants, along with a lower compensatory increase of antioxidants when compared with polysulfone dialysis. In conclusion, a single HD session, even when conducted with a biocompatible membrane, appears to play an important role in the imbalance between ROS production and antioxidant defense, but to a milder extent than cuprophane dialysis.
\end{abstract}

Keywords: oxidative stress, antioxidants, hemodialysis, biocompatibility, membranes

\section{Introduction}

Oxidative stress, resulting from an imbalance between reactive oxygen species (ROS) and reactive nitrogen species (RNS) production and antioxidant defense mechanisms, is a well recognized phenomenon in hemodialysis (HD) patients. There is a growing body of evidence implicating increased oxidative stress and inflammation in the genesis of cardiovascular atherosclerotic diseases, that are the leading causes of morbidity and mortality in the HD population. ${ }^{1}$ Increased oxidative stress in HD patients may arise from uremia-associated metabolic/humoral abnormalities and the bioincompatibility of the HD procedure (dialyzer membrane and pyrogen component of the dialyzate).

In normal conditions, free oxygen radicals (such as $\mathrm{O}_{2}^{-}$, hydoxyl radicals, hydroxy peroxide) serve as part of nonspecific defense mechanisms in the organism (for instance, against infectious factors); however, they may become toxic when they are overproduced or because of alterations in cellular mechanisms of protection. ${ }^{3}$ Several markers of oxidative stress have been identified, such as the lipid peroxidation product, malondialdehyde (MDA), advanced glycosylation end products, advanced oxidation protein products, and enhanced susceptibility of low-density lipoprotein (LDL) to ex vivo oxidation. ${ }^{2,3}$ Increased RNS also contributes to oxidative stress, as indicated 
by the fact that an impaired nitric oxide (NO) synthetic pathway plays a key role in mediating renal injury. ${ }^{4}$ Antioxidant mechanisms that serve as a safeguard against highly reactive oxygen radicals seem to be impaired in HD patients. These may be enzymatic (such as superoxide dismutase [SOD], catalase $[\mathrm{CAT}]$, and glutathione peroxidase [GSH-Px]) or extracellular antioxidant defense elements (such as reduced glutathione [GSH]). ${ }^{5}$ Furthermore, hydrophilic and lipophilic antioxidant vitamins are altered in uremia, ie, vitamin $E$ levels in erythrocytes and mononuclear cells are low despite normal plasma levels, and a dramatic depletion of vitamin $\mathrm{C}$ is also observed..$^{6,7}$

Uremic state and hemobioincompatibility are now regarded as the major culprits responsible for subclinical inflammation and oxidative stress and, therefore, progression of accelerated atherosclerosis. Measurement of oxidative stress could be useful to investigate its role, not only in the initiation and development of chronic uremic complications, but also to evaluate preventive actions, including antioxidative therapy and use of more biocompatible membranes during HD.

The aim of this study was to explore the net oxidative effect produced by a single HD procedure, based on a comparison of two different dialysis membranes, ie, cellulosic cuprophane and synthetic polysulfone in chronic HD patients. We determined serum MDA as an indicator of lipid peroxidation, plasma protein carbonyl content (PCO) as a marker of oxidative protein damage, and serum nitrite/nitrate levels as indicators of RNS production. We measured erythrocyte GSH level, CAT, SOD, and GSH-Px activity, and serum vitamin E and vitamin $\mathrm{C}$ levels as antioxidant markers.

\section{Methods}

The investigation conformed to the principles outlined in the Declaration of Helsinki. The study was approved by the local ethics committee, and all participants gave informed consent.

\section{Subjects and study design}

Fifteen nondiabetic HD patients (nine men and six women, mean age $58.3 \pm 2.3$ years, mean HD duration $38.3 \pm 6.7$ months) with a history of end-stage renal disease (ESRD), in the absence of any clinical or laboratory documentation of atherosclerotic disease, or systemic pathologies, such as active infection, inflammatory disease, or malignancy, were included in this random, cross-controlled study. Etiologies for ESRD were primary hypertension in 10, nephrolithiasis in two, chronic glomerulonephritis in one, polycystic kidney disease in one, and unknown in one. For recruitment purposes, the following criteria was considered:

1. Duration of HD of not less than one year.

2. Hemodialysis treatment three times weekly with a synthetic or semisynthetic membrane, each session lasting four hours, with a bicarbonate dialyzate.

3. Documentation of adequate dialysis based on good clinical status, satisfactory laboratory data, and a KT/V value $\geq 1.3$.

Hemodialysis patients meeting the above criteria were dialyzed with a cuprophane membrane in a single HD session, then dialyzed using their regular membranes for the following two weeks. At the end of this period, they were dialyzed with a polysulfone membrane in another single HD session. Venous blood samples for oxidative stress markers were taken immediately before and after these two index HD sessions to study the effects of the two different dialysis membranes. Oxidative stress parameters were also studied at baseline in blood samples of both patient and healthy control groups.

Fifteen individuals (nine men and six women of mean age $57.3 \pm 2.2$ years) proven to be healthy and free from any signs of chronic disease after careful clinical and laboratory examination were included in the study as the control group. Control subjects had a mean serum creatinine of $0.77 \pm 0.20 \mathrm{mg} / \mathrm{dL}$ and were considered to be normotensive on the basis of blood pressure measurements (mean systolic blood pressure $118 \pm 10 \mathrm{mmHg}$ and mean diastolic pressure $76 \pm 3 \mathrm{mmHg}$ ). None of the study subjects were active cigarette or alcohol consumers, and those who were on pre-existing antioxidant supplements, such as vitamin $\mathrm{C}$ and $\mathrm{E}$, were excluded from the study.

\section{Determination of oxidative} stress markers

Fasting blood samples were collected from all subjects without an anticoagulant. In HD patients, blood samples were collected before the first weekly HD treatment. Serum was obtained by centrifugation at $3000 \times \mathrm{g}$ for 10 minutes. Hemolysates were prepared from samples collected into vacuum tubes containing $1.7 \mathrm{mg} / \mathrm{mL} \mathrm{K}_{3}$ ethylenediamine tetra-acetic acid (EDTA) as an anticoagulant. After centrifugation at $3000 \times \mathrm{g}$ for 15 minutes, plasma and buffy coat were removed from the pellet.

Red blood cells were washed three times in an ice-cold isotonic saline $(1: 10 ; \mathrm{v} / \mathrm{v})$, and were resuspended in a washing solution to give a $50 \%$ suspension. Hemolysate obtained was divided into two aliquots. One aliquot was used to determine the hemoglobin concentration by the cyanomethemoglobin method. ${ }^{8}$ The second aliquot was used for spectrophotometric determination of the enzymatic activities of SOD, CAT, and GSH-Px. 
Serum thiobarbituric acid-reactive substances in serum were determined by the fluorometric method, ${ }^{9}$ and the results were expressed as nmol/mL MDA. Carbonyl content in oxidatively modified proteins was determined as previously described..$^{10}$ The absorbance of the sample was measured at $360 \mathrm{~nm}$ and the results were given as $\mu \mathrm{mol} / \mathrm{L}$ carbonyl using $\varepsilon$ $\max 22,000 \mathrm{M}^{-1} \mathrm{~cm}^{-1}$. Serum nitrite and nitrate levels were measured using the methods of Kader and Bories, respectively. ${ }^{11,12}$ Serum vitamin E concentration was measured as described by Desai using a standard curve of known concentrations of D- $\alpha$-tocopherol acetate. ${ }^{13}$ Vitamin $\mathrm{C}$ concentrations were measured in serum by the method of McCormick. ${ }^{14}$ Ascorbic acid was oxidized by $\mathrm{Cu}^{2+}$ to form dehydroascorbic acid which reacts with acidic 2,4-dinitrophenylhydrazine to form a red bis-hydrozone which was measured at $520 \mathrm{~nm}$. Erythrocyte concentration of the reduced GSH was measured using the method of Fairbanks and Klee. ${ }^{8}$ The results were expressed as $\mathrm{mg} / \mathrm{gHb}$. In the hemolysates obtained as mentioned above, the enzymatic activities of SOD, CAT, and GSH-Px were measured. The results were expressed as $\mathrm{U} / \mathrm{gHb}$ for $\mathrm{SOD}$ and GSH-Px, and as $\mathrm{k} / \mathrm{gHb}$ for CAT, where $\mathrm{k}$ is the rate constant for CAT activity. Erythrocyte Cu, Zn-SOD activity was assayed by the spectrophotometric indirect inhibition technique of Misra and Fridovic. ${ }^{15}$ CAT activity in erythrocytes was measured by the method described by Aebi using hydrogen peroxide as substrate ${ }^{16} \mathrm{GSH}-\mathrm{Px}$ activity was measured in erythrocytes using $t$-butyl hydroperoxide as a substrate. ${ }^{17}$

\section{Statistical analysis}

Statistical analysis was performed using SPSS software (SPSS 10.0 for Windows [SPSS/PC; SPSS Inc., Chicago, IL]). Continuous variables were expressed as mean \pm standard error of measurement (SE). The independent t-test and paired t-test were used to compare the means for continuous variables with normal distribution. The Mann-Whitney $U$ test and Wilcoxon test were used for the analysis of data with nonnormal distribution. $P<0.05$ was considered statistically significant.

\section{Results}

Patient and control groups did not differ significantly from each other with respect to age and gender, as described in the Methods section.

Baseline oxidative stress and antioxidant parameters are shown in Table 1. When compared with the control group, HD patients had statistically higher levels of MDA, an indicator of lipid peroxidation, and higher protein carbonyl content, an indicator of oxidative protein damage. Plasma nitrite levels
Table I Comparison of HD patients and healthy controls with respect to baseline oxidative stress parameters (mean $\pm \mathrm{SE}$ )

\begin{tabular}{llll}
\hline & $\begin{array}{l}\text { Controls } \\
(\mathbf{n}=\mathbf{I 5})\end{array}$ & $\begin{array}{l}\text { HD patients } \\
(\mathbf{n}=\mathbf{I 5})\end{array}$ & $\boldsymbol{P}$ \\
\hline $\mathrm{MDA}, \mathrm{nmol} / \mathrm{mL}$ & $1.09 \pm 0.04$ & $1.35 \pm 0.04$ & 0.01 \\
$\mathrm{PCO}, \mu \mathrm{mol} / \mathrm{L}$ & $55.7 \pm 1.3$ & $73.87 \pm 3.9$ & 0.000 \\
$\mathrm{GSH}, \mathrm{mg} / \mathrm{gHb}$ & $2.45 \pm 0.09$ & $2.68 \pm 0.10$ & 0.12 \\
$\mathrm{Vit} \mathrm{C}, \mathrm{mg} / \mathrm{dL}$ & $0.59 \pm 0.07$ & $1.8 \mathrm{I} \pm 0.16$ & 0.000 \\
$\mathrm{Vit} \mathrm{E}, \mu \mathrm{mol} / \mathrm{L}$ & $57.9 \pm 0.07$ & $53.6 \pm 1.35$ & 0.082 \\
$\mathrm{SOD}, \mathrm{U} / \mathrm{gHb})$ & $1703 \pm 32$ & $1 \mathrm{II} \pm 24$ & 0.000 \\
$\mathrm{CAT}, \mathrm{k} / \mathrm{gHb}$ & $248 \pm 14$ & $261 \pm 8.5$ & 0.000 \\
$\mathrm{GSH}-\mathrm{Px}, \mathrm{U} / \mathrm{gHb}$ & $2.68 \pm 0.10$ & $1.87 \pm 0.09$ & 0.000 \\
Nitrite, $\mu \mathrm{mol} / \mathrm{L}$ & $0.64 \pm 0.02$ & $2.36 \pm 0.12$ & 0.000 \\
Nitrate, $\mathrm{nmol} / \mathrm{L}$ & $\mathrm{I} .14 \pm 0.01$ & $0.18 \pm 0.01$ & 0.108 \\
\hline
\end{tabular}

Abbreviations: HD, hemodialysis; MDA, malondialdehyde; PCO, protein carbonyl content; GSH, glutathione; GSH-Px, GSH peroxidase; vit C, vitamin C; vit E, vitamin E; SOD, superoxide dismutase; CAT, catalase.

were increased in uremic patients, whereas no significant change was observed in nitrate levels between the groups.

No significant difference was observed in serum GSH levels and vitamin E levels between the groups; however, the vitamin $\mathrm{C}$ level was found to be higher in the HD group. Antioxidant enzymes, including SOD and GSH-Px, were lower in patients undergoing HD compared with controls, as opposed to the CAT level which was found to be higher in HD patients.

\section{Effect of dialysis with cuprophane membrane on oxidative stress}

The changes in oxidative stress parameters after a HD session using the cuprophane membrane are shown in Table 2. Both

Table 2 Changes in oxidative stress parameter levels in patients using a cuprophane membrane, before and after a HD session (mean $\pm \mathrm{SE}$ )

\begin{tabular}{llll}
\hline & Before HD & After HD & $P$ \\
\hline MDA, $\mathrm{nmol} / \mathrm{mL}$ & $\mathrm{I} .35 \pm 0.08$ & $1.62 \pm 0.07$ & 0.000 \\
$\mathrm{PCO}, \mu \mathrm{mol} / \mathrm{L}$ & $73.8 \pm 3.9$ & $79.1 \pm 3.7$ & 0.038 \\
$\mathrm{GSH}, \mathrm{mg} / \mathrm{gHb}$ & $2.68 \pm 0.10$ & $2.42 \pm 0.08$ & 0.019 \\
$\mathrm{Vit} \mathrm{C}, \mathrm{mg} / \mathrm{dL}$ & $\mathrm{I} .81 \pm 0.16$ & $0.97 \pm 0.09$ & $0.00 \mathrm{I}$ \\
$\mathrm{Vit} \mathrm{E}, \mu \mathrm{mol} / \mathrm{L}$ & $53.6 \pm 1.35$ & $53.4 \pm 1.74$ & 0.926 \\
$\mathrm{SOD}, \mathrm{U} / \mathrm{gHb})$ & $1 \mathrm{l} 16 \pm 24$ & $1213 \pm 98$ & 0.000 \\
$\mathrm{CAT}, \mathrm{k} / \mathrm{gHb}$ & $261 \pm 8.5$ & $287 \pm \mathrm{II}$ & 0.005 \\
GSH-Px, U/gHb & $1.87 \pm 0.09$ & $2.19 \pm 0.09$ & 0.000 \\
Nitrite, $\mu \mathrm{mol} / \mathrm{L}$ & $2.36 \pm 0.12$ & $1.94 \pm 0.1 \mathrm{I}$ & 0.000 \\
Nitrate, $\mathrm{nmol} / \mathrm{L}$ & $0.18 \pm 0.01$ & $0.09 \pm 0.008$ & 0.000 \\
\hline
\end{tabular}

Abbreviations: $\mathrm{HD}$, hemodialysis; MDA, malondialdehyde; $\mathrm{PCO}$, protein carbony content; GSH, glutathione; GSH-Px, GSH peroxidase; vit C, vitamin C; vit E, vitamin E; SOD, superoxide dismutase; CAT, catalase. 
MDA and PCO levels were found to be significantly increased after a dialysis procedure with the cuprophane membrane. Serum GSH and vitamin C levels were found to be decreased, whereas no change was observed in vitamin $E$ levels, after a HD procedure using the cuprophane membrane. As for the antioxidant enzymes, SOD, CAT, and GSH-Px levels were all significantly increased at the end of the HD session. Serum nitrite and nitrate levels were found to be decreased at the end of dialysis.

\section{Effect of dialysis with polysulfone membrane on oxidative stress}

The changes in oxidative stress parameters after a HD session with a polysulfone membrane are shown in Table 3 . Both MDA and PCO levels were found to be higher after a dialysis session with the polysulfone membrane; however, the increase in PCO level did not reach statistical significance. Serum GSH and vitamin $\mathrm{C}$ levels were found to be decreased, whereas an increase was observed in vitamin $\mathrm{E}$ levels, after an HD procedure with the polysulfone membrane. The levels of antioxidant enzymes, including SOD, CAT, and GSH-Px, were all significantly increased during that HD session, similar to what was observed using the cuprophane membrane. Serum nitrite and nitrate levels were found to be decreased in the same session, as was the case with the cuprophane membrane.

\section{Comparison of the impacts of two different dialysis membranes on oxidative stress}

Comparison of the changes in oxidative stress parameter levels ( $\Delta$ levels) using cuprophane and polysulfone membranes after

Table 3 Changes in oxidative stress parameter levels in patients using a polysulfone membrane, before and after a HD session (mean $\pm \mathrm{SE})$

\begin{tabular}{llll}
\hline & Before HD & After HD & $P$ \\
\hline MDA, nmol/mL & $1.25 \pm 0.04$ & $1.34 \pm 0.04$ & 0.000 \\
$\mathrm{PCO}, \mu \mathrm{mol} / \mathrm{L}$ & $72.1 \pm 3.5$ & $78.7 \pm 5.6$ & 0.303 \\
$\mathrm{GSH}, \mathrm{mg} / \mathrm{gHb}$ & $2.58 \pm 0.10$ & $2.01 \pm 0.07$ & 0.000 \\
$\mathrm{Vit} \mathrm{C}, \mathrm{mg} / \mathrm{dL}$ & $2.07 \pm 0.12$ & $1.01 \pm 0.09$ & 0.000 \\
Vit $\mathrm{E}, \mu \mathrm{mol} / \mathrm{L}$ & $53.2 \pm 1.35$ & $57.7 \pm 1.12$ & 0.000 \\
$\mathrm{SOD}, \mathrm{U} / \mathrm{gHb})$ & $1130 \pm 24$ & $1220 \pm 34$ & 0.000 \\
$\mathrm{CAT}, \mathrm{k} / \mathrm{gHb}$ & $235 \pm 18$ & $353 \pm 36$ & 0.000 \\
GSH-Px, U/gHb & $2.07 \pm 0.08$ & $2.43 \pm 0.15$ & 0.002 \\
Nitrite, $\mu \mathrm{mol} / \mathrm{L}$ & $1.79 \pm 0.09$ & $1.42 \pm 0.09$ & 0.002 \\
Nitrate, $\mathrm{nmol} / \mathrm{L}$ & $0.22 \pm 0.02$ & $0.12 \pm 0.01$ & 0.006 \\
\hline
\end{tabular}

Abbreviations: HD, hemodialysis; MDA, malondialdehyde; PCO, protein carbonyl content; GSH, glutathione; GSH-Px, GSH peroxidase; vit C, vitamin C; vit E, vitamin E; SOD, superoxide dismutase; CAT, catalase. an HD session is shown in Table 4. A dialysis session with the cuprophane membrane was found to cause a significantly greater increase in MDA levels when compared with the polysulfone membrane. There was no difference in PCO levels between the two dialysis membranes. A dialysis session with the polysulfone membrane was found to lower GSH levels much more than the cuprophane membrane. On the other hand, an increase in vitamin E levels was observed using the polysulfone membrane, an effect which was absent with the cuprophane membrane. No significant change was observed in vitamin $\mathrm{C}$ levels between the two membranes. There were also no significant differences in SOD and GSH-Px levels between the polysulfone and cuprophane membranes. However, dialysis with the polysulfone membrane caused a significantly greater increase in CAT levels than with the cuprophane membrane. There were no differences in nitrite and nitrate levels between the two membranes.

\section{Discussion}

This study was performed to analyze whether a single dialysis procedure induces a respective net oxidative balance, based on a comparison of two dialysis membranes with different biocompatibility features, ie, cuprophane and polysulfone, in chronic HD patients. Our major finding was that a single dialysis session, even with a biocompatible membrane such as polysulfone, contributes to oxidant/antioxidant imbalance, but to a milder extent than cuprophane dialysis.

We have shown that a dialysis session with a cuprophane or polysulfone membrane caused increased levels of MDA, an index of lipid peroxidation. However, the increase was more

Table 4 Comparison of the changes in oxidative stress parameter levels ( $\Delta$ levels) using cuprophane and polysulfone membranes after a HD session (mean $\pm \mathrm{SE}$ )

\begin{tabular}{llll}
\hline & Polysulfone & Cuprophane & $P$ \\
\hline MDA, nmol/mL & $0.09 \pm 0.003$ & $0.27 \pm 0.03$ & 0.000 \\
$\mathrm{PCO}, \mu \mathrm{mol} / \mathrm{L}$ & $6.61 \pm 6.2$ & $5.3 \pm 2.3$ & 0.843 \\
$\mathrm{GSH}, \mathrm{mg} / \mathrm{gHb}$ & $-0.57 \pm 0.08$ & $-0.26 \pm 0.09$ & 0.024 \\
$\mathrm{Vit} \mathrm{C}, \mathrm{mg} / \mathrm{dL}$ & $-1.06 \pm 0.15$ & $-0.84 \pm 0.19$ & 0.372 \\
$\mathrm{Vit} \mathrm{E}, \mu \mathrm{mol} / \mathrm{L}$ & $4.5 \pm 0.40$ & $-0.2 \pm 1.92$ & 0.032 \\
$\mathrm{SOD}, \mathrm{U} / \mathrm{gHb})$ & $90 \pm 15$ & $97 \pm 12$ & 0.730 \\
$\mathrm{CAT}, \mathrm{k} / \mathrm{gHb}$ & $\mathrm{I} / 8 \pm 30$ & $26 \pm 7.6$ & 0.009 \\
$\mathrm{GSH}-\mathrm{Px}, \mathrm{U} / \mathrm{gHb}$ & $0.36 \pm 0.09$ & $0.32 \pm 0.16$ & 0.529 \\
Nitrite, $\mu \mathrm{mol} / \mathrm{L}$ & $-0.37 \pm 0.09$ & $-0.42 \pm 0.08$ & 0.717 \\
Nitrate, $\mathrm{nmol} / \mathrm{L}$ & $-0.10 \pm 0.03$ & $-0.09 \pm 0.01$ & $0.58 \mathrm{I}$ \\
\hline
\end{tabular}

Abbreviations: HD, hemodialysis; MDA, malondialdehyde; PCO, protein carbonyl content; GSH, glutathione; GSH-Px, GSH peroxidase; vit C, vitamin C; vit E, vitamin E; SOD, superoxide dismutase; CAT, catalase. 
marked with cuprophane than with polysulfone. Although there are controversial results in the literature indicating that HD could improve lipid profiles in patients with a previous pro-oxidative state such as uremia, ${ }^{18}$ our findings are in accordance with the findings of others who have indicated an increase in lipid peroxidation during dialysis. ${ }^{19}$ Interaction of circulating blood with the hemodialytic system causes bioincompatibility reactions, such as production of ROS by inflammatory cells due to complement-dependent or complement-independent pathways. ${ }^{19}$ The ultimate result is an increase in inflammatory reactions characterised by triggering of a respiratory burst, and synthesis and release of inflammatory mediators. Plasma levels of inflammatory cytokines (such as interleukin-1, interleukin-6, and tumor necrosis factor- $\alpha$ ) are elevated in dialysis patients, and their expression was exacerbated further even after a single dialysis. ${ }^{20}$ The majority of ROS generated from activated polymorphonuclear leukocytes is hydrogen peroxide which causes subsequent lipid peroxidation. Oxidative stress and alterations in lipid metabolism observed in HD are important because it enhances the susceptibility of LDL oxidation which is recognised as the major initiating event in the genesis of atherosclerosis. Besides the alterations in lipid levels, oxidative stress also involves protein moieties in uremic patients. ${ }^{21}$ We found PSO, an indicator of oxidative protein damage, to be higher in HD patients compared with controls. PCO level increased after a dialysis procedure with both membranes, although it did not reach statistical significance with the polysulfone membrane. The levels of difference in PCO content between groups was similar, indicating that both dialysis membrane types may contribute to increased oxidative stress at the protein level as well.

Plasma nitrite levels were found to be higher in HD patients than in normal controls, indicating a high RNS production in the uremic population. $\mathrm{NO}$ actively reacts with superoxide $\left(\mathrm{O}_{2}^{-}\right)$and other ROS to produce peroxynitrite, a highly cytotoxic ROS. Peroxynitrite was shown to induce oxidative damage to DNA, lipids, and proteins in vascular cells, all of which contribute to cellular damage and progression of atherosclerosis. ${ }^{22}$ A putative cause for excessive NO production in uremia could be guanidino compounds that accumulate in the circulation of uremic patients and upregulate NO synthesis. Another possible cause of increased NO is its higher release from systemic vessels due to augmented expression of both inducible and endothelial nitric oxide synthase. Most studies indicate that NO increases early during dialysis, possibly due to heparin or leukocyte activation by the dialysis membrane, both of which are potential inducers of NO production; however, a significant drop in NO levels usually occurs at the end of dialysis. ${ }^{23}$ As opposed to increased postdialysis levels of other oxidants, such as MDA and PCO, we have found postdialysis nitrite and nitrate levels to be lower than predialysis values, indicating that NO elimination during dialysis prevails production and returns to high levels between HD sessions.

Our results indicate that, with the exception of CAT, antioxidant enzymes (SOD and GSH-Px) representing the early lines of defense against oxidative attack, are lower in patients undergoing HD compared with healthy controls. This finding is confirmed by other research. ${ }^{24}$ Some studies have indicated impairment of antioxidant systems and augmentation of oxidants during HD sessions. ${ }^{25}$ Our results show that all antioxidant enzymes (including SOD, CAT, and GSH-Px) were significantly increased after an HD session. The level of increase was not different for SOD and GSH-Px between the two type of membranes; however, CAT levels increased more with the polysulfone membrane. These results suggest that the increase in oxidant products after a dialysis session is accompanied by compensatory increases in the antioxidant mechanism of erythrocytes in scavenging ROS. However, that mechanism is not sufficient to restore the balance, reflecting compromised antioxidant defense. Interestingly, we found that GSH levels, which were similar at baseline between patients and controls, were decreased after a dialysis. The observed decrease in intracellular GSH during a dialysis session points to either a consumption or a loss of GSH during dialysis, rather than to an effect of uremia. ${ }^{26}$

We have found vitamin $\mathrm{C}$ levels to be higher in HD patients compared with normal subjects. However, vitamin E levels did not differ between the groups. Most other studies have found plasma vitamin E levels to be normal but vitamin $\mathrm{C}$ levels to be reduced in uremic subjects. ${ }^{27}$ The unexpectedly high vitamin $\mathrm{C}$ levels in HD patients in this study suggests that vitamin $\mathrm{C}$ concentration might have increased in excess of other uremic pro-oxidant substances. Metabolites have been reported to be derived from ascorbic acid oxidation during HD, with a significant increase in ascorbyl-free radicals. ${ }^{23}$ The ratio of ascorbic acid to oxidised ascorbic acid is usually tightly regulated, which is further supported by the presence of high ascorbate concentrations in tissues with relatively high fluxes of oxidants. ${ }^{28}$ The high vitamin $\mathrm{C}$ levels observed in the HD patients in our study need to be confirmed by further studies. Vitamin $\mathrm{C}$ is an effective antioxidant against lipid peroxidation because of its ability to destroy free radicals and regenerate $\alpha$-tocopherol from tocopherol radicals. In accordance with other studies, ${ }^{7}$ we 
have found postdialysis vitamin $\mathrm{C}$ levels to be decreased by almost $50 \%$, which is likely to be due to the filtration of this low molecular weight compound through the membrane. On the other hand, lipophilic vitamin $\mathrm{E}$ is not filtered by the membrane. Our findings indicate an increase in vitamin $\mathrm{E}$ levels using a polysulfone membrane, an effect which was absent with a cuprophane membrane. In uremia, vitamin $\mathrm{E}$ levels in erythrocytes and mononuclear cells have been shown to be low despite normal plasma levels, ${ }^{6}$ in agreement with our work showing comparable serum levels of vitamin $\mathrm{E}$ in both uremic patients and control groups. Although other studies indicate that vitamin E concentration is not modified by $\mathrm{HD},{ }^{23}$ our finding of increased concentration of vitamin $\mathrm{E}$ raises the possibility that the polysulfone membrane might have increased the bioactivity of vitamin $\mathrm{E}$ in the setting of more favorable hemobiocompatibility.

Our results have also shown that HD patients had a trend towards increased oxidant state and depletion of antioxidants in comparison with normal controls. In our previous study, we demonstrated increased oxidative status and a defective antioxidative defense system starting from the early stages of chronic renal failure, ${ }^{5}$ showing that defence mechanism impairment is, at least in part, independent of the dialysis procedure. Overall, the absence of complete correction of uremia together with untoward effects of dialysis can lead to oxidative stress caused by abnormal production of oxidants and defective antioxidant protection. The degree of HD-associated increase in oxidative stress varies according to the dialysis membrane used. It was previously reported that, with respect to induction of oxidative DNA damage and MDA formation, polysulfone and cellulosic membranes maximally differed by about 50 and 70 percent, respectively. ${ }^{29}$ Moreover, some studies point out that polysulfone improves the ROS/antioxidant ratio. ${ }^{24}$

In conclusion, HD patients face marked disturbance in the extracellular redox system in the setting of uremia, which is exacerbated by a dialysis procedure. A single HD session, even when conducted with a biocompatible membrane, appears to play an important role in the imbalance between ROS production and antioxidant defense. Therefore, it is worthy of consideration that increased oxidative stress is an important therapeutic target for pharmacologic therapy and palliation of hemoincompatibility of a dialysis system in uremic patients undergoing HD.

\section{Disclosures}

The authors report no conflicts of interest in this work.

\section{References}

1. Himmelfard J, Stenvinkel P, Ikizler TA, Hakim RA. The elephant in uremia: Oxidant stres as a unifying concept of cardiovascular disease in uremia. Kidney Int. 2002;62(5):1524-1538.

2. Esterbauer H, Gebicki J, Puhl H, Jurgens G. The role of lipid peroxidation and antioxidants in oxidative modification of LDL. Free Radic Biol Med. 1992;13(4):341-390.

3. Halliwell B. Free radicals and antioxidants. A personal view. Nutr Rev. 1994;52(8 Pt 1):253-265.

4. Aiello S, Noris M, Remuzzi G. Nitric oxide/L-arginine in uremia. Miner Electrolyte Metab. 1999;25(4-6):384-390.

5. Dursun B, Dursun E, Capraz I, Ozben T, Apaydin A, Suleymanlar G. Are uremia, diabetes and atherosclerosis linked with impaired antioxidant mechanisms? J Invest Med. 2008;56(2):545-552.

6. Galli F, Canestrari F, Buoncristiani U. Biological effects of oxidative stress in hemodialysis: The possible roles of vitamin E. Blood Purif. 1999;17(2-3):79-94.

7. Bohm V, Tiroke k, Schneider S, Sperschneider H, Stein G, Bitsch R. Vitamin C status of patients with chronic renal failure, dialysis patients and after renal transplantation. Int J Vitam Nutr Res. 1997;67(4): 262-266.

8. Fairbanks VF, Klee GG. Biochemical aspects of hematology. In: Tietz NW, editor. Textbook of Clinical Biochemistry. Philadelphia, PA: WB Saunders Company; 1986:1498-1535.

9. Wasowicz W, Neve J, Peretz A. Optimized steps in fluorometric determination of thiobarbituric acid reactive substances in serum: Importance of extraction $\mathrm{pH}$ and influence of sample preservation and storage. Clin Chem. 1993;39(12):2522-2526.

10. Reznick AZ, Packer L. Oxidative damage to proteins: Spectrophotometric method for carbonyl assay. Methods Enzymol. 1994;233:357-363.

11. Kader A, Frazzini VI, Solomon RA, Trifiletti RR. Nitric oxide production during focal cerebral ischemia in rats. Stroke. 1993;24(11):1709-1716.

12. Bories PN, Bories C. Nitrate determination in biological fluids by an enzymatic one-step assay with nitrate reductase. Clin Chem. 1995;41(6 Pt 1):904-907.

13. Desai ID. Vitamin E analysis methods for animal tissues. Methods Enzymol. 1984;105:138-147.

14. McCormick DB. Vitamins. In: Tietz NW, editor. Textbook of Clinical Chemistry. Philadelphia, PA: WB Saunders Company; 1986:949.

15. Misra HP, Fridovich I. The role of superoxide anion in the autoxidation of epinephrine and a simple assay for superoxide dismutase. $J$ Biol Chem. 1972;247(10):3170-3175.

16. Aebi HE. Catalase of enzymatic analysis. In: Bergmeyer HU, editor. Volume III Enzymes 1: Oxidoreductases, Transferases. Weinheim: VCH Verlagsgesellschaft; 1987:273-285.

17. Paglia DE, Valentine WN. Studies on the quantitative and qualitative characterization of erythrocyte glutathione peroxidase. J Lab Clin Med. 1967;70(1):158-169.

18. Ramos R, Gomez-Gerique N, Martinez-Castelao A. Lipoprotein oxidation profile in end stage renal disease patients. Role of vitamin $\mathrm{C}$ supplementation. Nephrologia. 2005;25(2):178-184.

19. Tetta C, Biasioli S, Schiavon R, et al. An overview of haemodialysis and oxidant stress. Blood Purif. 1999;17(2-3):118-126.

20. Descamps-Letscha B, Herbelin A, Nguyen AT, et al. Balance between IL-1 beta, TNF alpha, and their specific inhibitors in chronic renal failure and maintenance dialysis. Relationships with activation markers of T cells, B cells and monocytes. J Immunol. 1995;154(2):882-892.

21. Dursun E, Dursun B, Suleymanlar G, Ozben T. Carbonyl stress in chronic renal failure: The effect of hemodialysis. Ann Clin Biochem. 2005;42(Pt 1):64-66.

22. Ballinger SW, Patterson C, Yan CN, et al. Hydogen peroxide- and peroxynitrite-induced mitochondial DNA damage and dysfunction in vascular endothelial and smooth muscle cells. Circ Res. 2000;86(9): 960-966. 
23. Clermont G, Lecour S, Lahet J, et al. Alteration in plasma antioxidant capacities in chronic renal failure and hemodialysis patients: A possible explanation for increased cardiovascular risk in these patients. Cardiovasc Res. 2000;47(3):618-623.

24. Gonzalez-Diez B, Cavia M, Torres G, Abaigar P, Muniz P. Effect of a hemodiafiltration session with on-line regeneration of the ultrafiltrate on oxidative stress. Blood Purif. 2008;26(6):505-510.

25. Mayer B, Zitta S, Greilberger J, et al. Effect of hemodialysis on the antioxidative properties of serum. Biochim Biophys Acta. 2003;1638(3):267-272.
26. Schettler V, Wieland E, Methe H, Schuff-Werner P, Muller GA. Oxidative stress during dialysis: Effect on free radical scavenging enzyme (FRSE) activities and glutathione (GSH) concentration in granulocytes. Nephrol Dial Transplant. 1998;13(10):2588-2593.

27. Morena M, Cristol JP, Bosc JY, et al. Convective and diffusive losses of vitamin $\mathrm{C}$ during a hemodiafiltration session: A contributive factor to oxidative stress in hemodialysis patients. Nephrol Dial Transplant. 2002;17(3):422-427.

28. Frei B, England L, Ames B. Ascorbate is an outstanding antioxidant in human blood plasma. Proc Natl Acad Sci U S A. 1989;86(16): 6377-6381.

\section{Publish your work in this journal}

The International Journal of Nephrology and Renovascular Disease is an international, peer-reviewed open-access journal focusing on the pathophysiology of the kidney and vascular supply. Epidemiology, screening, diagnosis, and treatment interventions are covered as well as basic science, biochemical and immunological studies. The journal welcomes original

Submit your manuscript here: http://www.dovepress.com/international-journal-of-nephrology-and-renovascular-disease-journal research, clinical studies, reviews \& evaluations, expert opinion and commentary, case reports and extended reports. The manuscript management system is completely online and includes a very quick and fair peerreview system, which is all easy to use. Visit http://www.dovepress.com/ testimonials.php to read real quotes from published authors. 